Case Reports

\title{
A case of hypertrophic cardiomyopathy secondary to dystrophinopathy
}

\author{
*Shilpa D Kulkarni ${ }^{1}$, Sumitra Venkatesh ${ }^{2}$, Varsha A Patil ${ }^{3}$
}

Sri Lanka Journal of Child Health, 2015; 44(4): 226-228

(Key words: Contiguous gene deletion, Duchenne muscular dystrophy, hypertrophic cardiomyopathy)

\section{Introduction}

Dystrophinopathies include a spectrum of muscle diseases caused by mutations in the Duchenne Muscular Dystrophy (DMD) gene which encodes the protein "dystrophin". Commonly, it presents as DMD or Becker Muscular Dystrophy ${ }^{1,2}$. Cases of DMD usually have dilated cardiomyopathy and a few have hypertrophic cardiomyopathy ${ }^{3}$. Contiguous gene deletion syndromes are disorders with coincident expression of otherwise unrelated inborn errors of metabolism. Xp21 deletion syndrome is a deletion syndrome most frequently affecting the X-linked congenital adrenal hypoplasia, glycerol kinase and dystrophin loci ${ }^{4}$. We present a floppy infant with hypertrophic cardiomyopathy who was subsequently diagnosed as DMD with a strong possibility of contiguous gene deletion syndrome in the family.

\section{Case report}

A 20 month old boy was born at term from a third degree consanguineous union with a birth weight of 3 $\mathrm{kg}$. His perinatal history was uneventful except for hyperbilirubinaemia requiring phototherapy. There was global developmental delay with only head holding and palmar grasp achieved by 18 months of age and cooing since 15 months of age. He had a history of repeated respiratory infections requiring hospitalization. On examination, he was dysmorphic with a flat facial profile, low set ears and hypertelorism. His head circumference was $48 \mathrm{~cm}$.

\footnotetext{
${ }^{1}$ Associate Professor, ${ }^{2}$ Assistant Professor, ${ }^{3}$ Fellow, Paediatric Neurology, Department of Paediatric Neurosciences, Bai Jerbai Wadia Hospital for Children, Mumbai, India

*Correspondence: skulkarni.shilpa@gmail.com (Received on 26 June 2014: Accepted after revision on 22 August 2014)

The authors declare that there are no conflicts of interest

Open Access Article published under the Creative Commons CC-BY-NC-ND Licence. (CC)
}

He had profound hypotonia, proximal muscle weakness, mild head lag and hyporeflexia. He had prominent calf muscles and hepatomegaly. Chest radiography showed cardiomegaly and abdominal ultrasonography confirmed hepatomegaly. Echocardiography showed hypertrophic cardiomyopathy with ventricular dysfunction. Serum alanine transferase and lactate dehydrogenase levels were high. Serum creatine kinase (CK) was high at 7,800 IU/litre. Random blood sugar and lactate levels were normal.

A differential diagnosis of Pompe disease was considered. However, in view of the family history of previous sibling death at eight months of age with floppiness, ambiguous genitalia and hypercreatine kinasemia, a contiguous gene deletion syndrome involving dystrophin gene (Xp21 deletion syndrome) was suspected. A multiplex ligation-dependent probe amplification (MLPA) study of the proband showed duplication of exons 53, 54 and 55 at Xp21 site of X chromosome. The child could not be revived and succumbed to pneumonia with cardiorespiratory failure. Parents were investigated along with two other live female siblings. None of them had hypercreatine kinasemia. The family refused further genetic studies.

\section{Discussion}

Dystrophin, the protein product of DMD gene, is the largest structural protein $(427 \mathrm{kD})$ that links the internal actin cytoskeleton of the muscle fibre to a raft of dystrophin associated glycoprotein (DAG) in the muscle membrane ${ }^{5}$. Its absence leads to increased membrane fragility, a loss of linkage across sarcolemma leading to disorganization of the DAG complex. This results in myofibril necrosis leading to cycles of degeneration and regeneration with eventual permanent loss of fibre and fibrotic replacement ${ }^{1}$. The availability of assays for gene and dystrophin protein have led to appreciation of variability in clinical presentation associated with dystrophin gene mutation $^{1,6}$. 
DMD classically presents between three and six years of age with skeletal muscle weakness preferentially affecting large proximal muscle groups. It is relentlessly progressive, leading to loss of ambulation by 11 to 13 years and death by the third decade, often due to respiratory insufficiency ${ }^{1}$. Cardiac involvement in DMD may precede musculoskeletal symptoms and is often unrelated to the extent of musculoskeletal involvement ${ }^{3}$. More than one third of patients with DMD develop signs of cardiac dysfunction by 14 years of age and virtually all have cardiomyopathy, often dilated, by 18 years of age $^{7}$. Cardiac dysfunction in DMD is due to early regional myocardial fibrosis leading to left ventricular dysfunction - systolic as well as diastolic. It is known that progression of hypertrophic cardiomyopathy to dilated or burnt out cardiomyopathy occurs in 10 $15 \%$ of patients ${ }^{8}$. Dystrophinopathy may also present as pure cardiac presentation as in the case of $\mathrm{X}$-linked cardiomyopathy which usually presents in the third decade of life ${ }^{1}$.

Our patient presented with severe hypotonia, proximal muscle weakness, cardiomegaly, hepatomegaly and pseudohypertrophy of calf muscles. Echocardiographic findings were consistent with hypertrophic cardiomyopathy. Our patient had a sibling with adrenal hypoplasia and muscular weakness who expired before genetic testing. He had ambiguous genitalia, global developmental delay, floppiness with weakness and hypercreatine kinasemia. In view of this significant history suggestive of a contiguous gene deletion syndrome, dystrophinopathy was thought of in our patient instead of a commonly presenting Pompe disease. The Multiplex Ligation-dependent Probe Amplification (MLPA) report was consistent with duplication involving Xp21 site of X chromosome at exons 53 to 55 . Thus, in the present case with hypertrophic cardiomyopathy, a diagnosis of dystrophinopathy could be confirmed with the help of molecular studies.

Schmickel (1986) first proposed the term contiguous gene syndrome for the group of disorders characterized by microdeletion or microduplication of chromosomal segments associated with clusters of single gene disorders ${ }^{9}$. Usually this syndrome is sporadic but it may be familial. Specific aspects of this syndrome could be clearly recognizable as single gene Mendelian trait. Xp21 contiguous gene deletion syndrome includes DMD, Aland Island eye disease, adrenal hypoplasia, glycerol kinase deficiency, ornithine transcarbamylase deficiency, retinitis pigmentosa and McLeod phenotype ${ }^{4}$.
A contiguous gene deletion syndrome should be kept in mind especially when multiple single gene disorders originating from deletion or duplication of a chromosomal segment are seen within a family; such deletions or duplications cannot be identified on routine karyotyping. Contiguous gene deletion syndromes, if unrecognized, may lead to delay in diagnosis and hence a missed opportunity for genetic counselling.

\section{References}

1. Beggs AH. Dystrophinopathy, the expanding phenotype. Dystrophin abnormalities in Xlinked dilated cardiomyopathy. Circulation 1997; 95: 2344-7.

http://dx.doi.org/10.1161/01.CIR.95.10.2344

2. Dystrophinopathies. In: Chen $\mathrm{H}$, editor. Atlas of Genetic Diagnosis and Counselling. $2^{\text {nd }}$ ed. New York: Springer; 2012. p. 331-7. http://dx.doi.org/10.1007/978-1-4614-10379_39

3. Park OY, Ahn Y, Park WS, Lim JH, Park HW, Kim JH, et al. Rapid progression from hypertrophic cardiomyopathy to heart failure in a patient with Becker muscular dystrophy. European Journal of Heart Failure 2005; 7: 684-8.

http://dx.doi.org/10.1016/j.ejheart.2004.07.0 19

PMid: 15921812

4. Cole DE, Clarke LA, Riddell DC, Samson KA, Seltzer WK, Salisbury S. Congenital adrenal hypoplasia, Duchenne muscular dystrophy, and glycerol kinase deficiency: importance of laboratory investigations in delineating a contiguous gene deletion syndrome. Clinical Chemistry 1994; 40: 2099-103.

PMid: 7955386

5. Davies KE, Nowak KJ. Molecular mechanisms of muscular dystrophies: old and new players. Nature Reviews Molecular Cell Biology 2006; 7: 762-73. http://dx.doi.org/10.1038/nrm2024

PMid: 16971897

6. Angelini C, Fanin M, Pegoraro E, Freda MP, Cadaldini M, Martinello F. Clinicalmolecular correlation in 104 mild X-linked muscular dystrophy patients: 
characterization of subclinical phenotypes. Neuromuscular Disorders 1994; 4: 349-58. http://dx.doi.org/10.1038/nrm2024

PMid: 16971897

7. Nigro G, Comi LI, Politano L, Bain RJ. The incidence and evolution of cardiomyopathy in Duchenne muscular dystrophy. International Journal of Cardiology 1990; 26: 271-7.

http://dx.doi.org/10.1016/01675273(90)9008 2-G
8. Spirito P, Bellone P. Natural history of hypertrophic cardiomyopathy. British Heart Journal 1994; 72(6 Suppl.): S10-S12. http://dx.doi.org/10.1136/hrt.72.6_Suppl.S10 PMid: 7873316

PMCid: PMC1025669

9. Schmickel RD. Contiguous gene syndromes: a component of recognizable syndromes. Journal of Pediatrics 1986; 109: 231-41 http://dx.doi.org/10.1016/S00223476(86)803 $77-8$ 